Max-Planck-Institut für demografische Forschung

Max Planck Institute for Demographic Research

Doberaner Strasse $114 \cdot$ D-18057 Rostock $\cdot$ GERMANY

Tel +49 (0) 3812081 - 0; Fax +49 (0) 3812081 - 202;

http://www.demogr.mpg.de

MPIDR WORKING PAPER WP 2002-012

FEBRUARY 2002

\title{
Divorce Risks of Swedish Women in \\ First Marriages: \\ Two cohorts born in 1950 and 1960
}

Liu, Guiping (liu@demogr.mpg.de)

This working paper has been approved for release by: Jan M. Hoem (hoem@demogr.mpg.de)

Head of the Laboratory of Contemporary European Fertility and Family Dynamics.

(C) Copyright is held by the authors.

Working papers of the Max Planck Institute for Demographic Research receive only limited review. Views or opinions expressed in working papers are attributable to the authors and do not necessarily reflect those of the Institute. 


\title{
Divorce Risks of Swedish Women in First Marriages
}

Two cohorts born in 1950 and 1960

\author{
Liu, Guiping \\ Max Planck Institute for Demographic Research \\ Doberaner Strasse 114, \\ 18057, Rostock, Germany \\ Liu@ demogr.mpg.de
}

27 February, 2002 


\title{
Divorce Risks of Swedish Women in First Marriages
}

Two cohorts born in 1950 and 1960

Liu, Guiping

\begin{abstract}
In this paper, we study first-marriage divorce risks in two cohorts of Swedish women, namely, those born in 1950 and 1960. We develop a hazard model with a piecewise-linear baseline log-hazard. First, we run the model without unobserved heterogeneity and second, we run the model with such a term. We have found a divorce pattern for Swedish women similar to what other researchers have found. Facilitated by having both cohort data and efficient software (aML), we were able to get a clear picture of the timing pattern of first marital dissolution risks. Our 1950 cohort model without unobserved heterogeneity does not produce any biased results; our 1960 cohort model with no unobserved heterogeneity overestimates the baseline hazard and evidently underestimates some of the coefficients.
\end{abstract}

Key words: cohort, divorce risk, Sweden 


\section{Introduction}

Divorce patterns of Swedish women is a subject that has of long been of interest to scholars. Gunnar Andersson (1997), for instance, made a comprehensive study of the impact of children on divorce risks of Swedish women. The variables he used included age at marriage, a premarital birth indicator, parity, the age of the youngest child, year of the marriage formation, and the duration of the marriage. According to researcher's studies (see also, Hoem, 1995; Hong, 1996; Erlangsen and Andersson, 2001), the usual pattern of divorce of Swedish women follows below:

Married teenagers are more divorce prone than older married people. Women who already had premarital children when they got married tend to have frail marriages. Childless women tend to be more vulnerable to marriage dissolution. The risk of divorce increases with the age of the youngest child. Finally, during the first two years after (the first) marriage formation, the divorce risks are much lower than for marriages beyond two years of duration.

In this article, we used the same covariates as Andersson employed. However, instead of a piecewise constant baseline model and RocaNova software, we employed a piecewise linear baseline model and aML software. Instead of focusing on period effects, we paid attention to the duration effects of the divorce pattern from a cohort perspective. We used the same Swedish Register Data set, but we selected cohorts of 1950 and 1960 as our study objects.

\section{Data and method}

\subsection{Data}

For this study, we used data from Swedish registers. The records from 1998 and 1999 were added to this database, which had previously only contained information up to 1997. As a preliminary study of the new data set, this paper did not use any newly added covariates but it did use the data from the two new years. There are two reasons why we chose two cohorts born in 1950 and 1960. The first is that the Swedish register data set is immense, containing 2,527,093 individuals. We decided to narrow our scope for the purpose of this study. The second reason for this choice 
is that cohort effects do make sense as a means of disclosing divorce patterns as a demographic tradition. The birth cohort perspective may, for example, display the consequences that changing attitudes have on divorce risks.

In the 1950 and 1960 cohorts, 53,299 of the 67,579 women and 48,249 of the 61,823 women were born in Sweden respectively. Because of the great number of cases, we were confident in making many categories of variables. Actually, most of our estimates are statistically significant with a $1 \%$ p-value, partly due to the ample information available. We only dealt with those observations with a 15-year marriage period or less. Younger birth cohorts, therefore, were not selected because they could not have had a marriage period beyond 15 years.

The records were censored either on the last day of December 1999, at the death of the women or their spouse, or in the case of migration (right censoring). As suggested by Hoem (1995), the records before 1968 were also censored because of the low quality of the data before this year (left censoring). Only a few cases from the two cohorts had any marital experience before 1968, therefore, the omission of the data before that year does not have any influence on our analysis.

\subsection{Method and model specification}

A difference between this and other similar studies is that an intensity regression model is applied in this study. Other scholars aforementioned used a piecewise linear baseline model. The mathematical formula in this study is as follow:

$$
\begin{aligned}
& \ln \mu_{i}(t)=y(t)+\sum_{k} z_{k}\left(u_{i k}+t\right)+\sum_{j} \alpha_{j} x_{i j}+\sum_{l} \beta_{l} w_{i l}(t)+v_{i} \\
& t=\text { duration since first marriage, } \\
& \text { where } \\
& \mu_{i}(t) \text { is the intensity of divorce at duration } t \text { for individual } i \text {, } \\
& \mathrm{y}(\mathrm{t}) \text { is the logarithm of baseline intensity, } \\
& z_{\mathrm{k}}\left(u_{i k}+t\right) \text { stands for duration splines, } \\
& u_{i k} \text { is the start point for invidual } \mathrm{i} \text {, spline number } \mathrm{k} \text {; } \\
& x_{i j} \text { stands for fixed covariates, } \\
& \alpha_{\mathrm{j}} \text { stands for coefficiants for fixed covariates, } \\
& w_{i l} \text { stands for time-varying covariates, } \\
& \beta_{1} \text { stands for coefficiants for time-varying covarites, } \\
& v_{i} \text { is to capture individual unobserved heterogeneity. }
\end{aligned}
$$


The above equation serves as a basic methodological explanation. It could have variants in the following process of analysis. For instance, if no unobserved heterogeneity effects were present, then the residual term would be left out of the equation. Parity could be ignored where the Child Age model, as we call it, was set up. The covariates waiting to be integrated into the model are summarized as follows:

Covariates

Fixed covariates:

Age at first marriage:

Premarital birth:

Time-varying covariates:

Parity:

Age of the youngest child:

Time variable:

\section{Levels}

16-19, 20-23, 24-28,29-35, 36-49;

no, yes;

$0,1,2,3,4+$

no child, pregnant, $0,1-2,3-5,6-8,9+$

duration of first marriage

(within 15 years of marriage).

It has been proven that all of these covariates had strong effects on divorce risks for Swedish women (see Hoem and Hoem, 1992; Hoem, 1995; Hong, 1996; Andersson, 1997). The covariates are exactly the same as those used in Gunnar Andersson's analysis (Andersson 1997), except that his covariate calendar-year was excluded here. (In the data preparation stage, however, this covariate was present.) Our intention was to focus on the cohort effects on divorce along with the duration of first marriages.

\section{General results}

Two covariates - parity and age of youngest child -have overlapping parts, namely, subgroups of parity 0 (for the former covariate) and childless (for the latter). To avoid confusion, we defined two separate models, one being the parity model, the other being the child age model. We have two independent data sets, namely one for the 1950 cohort and one for the 1960 cohort. Therefore, we analyzed the cohorts separately. In the following description of the results, we will present a general trend for each cohort and make some comparisons. Table 1 contains the summarized results for the parity model and the child age model without an unobserved heterogeneity component.

(Table 1 about here.) 


\subsection{Age at first marriage}

We observed a usual demographic finding, that is, teenagers had high risks of divorce for both cohorts. These divorce risks went down substantially when women got married after the age of 24. The relative divorce risk of teenagers from the 1960 cohort was particularly high, with a relative risk of 2.36 if the age group 24-28 is taken as a reference group (see the parity model in Table 1). Age at first marriage was included both in the parity model and in the child age model. Regarding this variable, the two models revealed the same pattern of divorce. Such stability across model specifications is reassuring.

\subsection{Premarital birth}

An indicator of premarital birth was integrated as a covariate into both the parity and child age models. In both models, women with pre-marital births had higher risks of getting divorced than women without pre-marital births. An interesting estimate obtained is that in the parity model, a model where the effect of age of the youngest child was left out, women with premarital births show much higher risks of divorce. In other words, when the effect of premarital birth was represented through the child age model, the gaps of the risks in the two categories of women became much lower. This may be due to the fact that in Sweden, a child is often born into a non-marital union that is later converted into marriage. We, therefore, are unable to observe the very young ages of the children (born outside of marriage) when disruption risks are normally low. Evidently, having a premarital child is much less important than the age of the youngest child in determining a Swedish woman's divorce risk.

By using aML's indirect referencing device for duration splines, duration effects for women with premarital births and for those without were presented separately. Figure 1 and Figure 2 show the interaction between the duration of marriage and the indicator of premarital birth.

(Figure 1 about here)

(Figure 2 about here)

Firstly, women with a premarital birth had a much higher risk of divorce in the time duration, except in the first year of marriage. Having a premarital birth made marriage temporarily stable for the first year, then unstable for most of the remaining 
marital duration. Secondly, the general pattern is the same in both cohorts, but women experienced a higher risk of divorce in the 1960 cohort than in the earlier cohort (See Figure 3a and Figure 3b). Finally, for both the 1950 and 1960 cohorts, the marital union entered a stable stage after 6 or 7 years in that divorce risks no longer increased.

(Figure $3 \mathrm{a} \& 3 \mathrm{~b}$ about here)

\subsection{Parity}

Referring to Table 1 again, childless women, as usual, were exposed to a higher risk of divorce than women with children. The divorce risk decreased as the parity increased. Having more than two children did not provide any important advantages for avoiding marriage dissolution. Perhaps this is because having two children used to be the commonly accepted ideal number of children in Sweden.

\section{4. Age of youngest child}

When turning to the age of the youngest child, we found similar results as those described by other scholars aforementioned. The effects as depicted in Table 1 are listed as follows. Childless women were exposed to the highest risk of divorce; being pregnant greatly protected women from marriage dissolution; mothers with an infant had the lowest risk of divorce; and when the youngest child grew older, the risk of marriage dissolution also grew.

A second, initially surprising result is that for almost every category of mothers, the 1960 cohort had a lower child-age-specific relative risk of divorce as compared to that of the baseline category "age 3-5 years old." Note that this doesn't mean that the 1960 cohort becomes less divorce-prone because these are relative risks that come from different baselines. As we have already seen in Figures $3 a$ \& $3 b$, the curve of the 1960 cohort shifted up above the curve of the 1950 cohort. If the baseline hazard represents the overall level of risks, this means that the 1960 cohort was more divorce-prone than the 1950 cohort. This conclusion will be further proved when we integrate the unobserved heterogeneity term into the model in section 4 of this paper.

We get further insights by including the interaction of parity and the age of the youngest child. This allows us to address the question of whether parity and the 
age of the youngest child independently affect the divorce pattern, or whether there are any joint-effects of these two covariates. In Figures $4 a \& 4 b$, one can find the results for the 1950 and the 1960 cohorts respectively, after the interactions are made. The curves on these two figures are not parallel: this implies that dependent effect as well as independent effect did exist between parity and the age of the youngest child.

(Figure $4 \mathrm{a}$ about here.)

(Figure $4 b$ about here.)

A woman with her youngest child in its first year of life had the lowest divorce risk. If a woman had a youngest child under age one or between the ages of one and two, the parity had very little effect on her divorce risk. This finding is especially true for the 1950 cohort. However, if a woman was pregnant, the parity did display a different pattern: the more children the woman already had, the more likely the woman was to experience a divorce. This conclusion holds true for both the 1950 and 1960 cohorts. Another interesting phenomenon for both cohorts is that parity 2 and parity 3 had identical effects for the age of the youngest child. The divorce risk of women who had four or more children was higher and was almost proportional to women with 2 and 3 children. In both the 1950 cohort and the 1960 cohort, women with one child show a "deviant" pattern of divorce, with a risk well above those with 2, 3, or 4 and more children. Women in the 1950 cohort with one child even had higher divorce risks than corresponding childless women when the child was more than five years old. We assume that selection effects may be especially strong for this group of women. Perhaps they did not want any more children because their marriage was unstable and they were waiting for marriage dissolution. Selection may exist among women who were pregnant, too. We actually wondered why being pregnant did not prevent marriage dissolution more strongly than it did.

\section{Modeling with unobserved heterogeneity}

The above description is based on hazard models without unobserved heterogeneity. What would happen if we run a model with an unobserved heterogeneity term? 
Would the new model reveal new patterns of divorce for Swedish women and would some of the previous conclusions have to be revised?

We have received the results from running models (the child age model of Table 1) for the 1950 cohort and the 1960 cohort respectively. The unobserved heterogeneity terms were added into these models in order to capture unobserved heterogeneity. The standard deviation for the 1950 cohort is relatively small $(0.270$, with a standard error of 0.260$)$, but quite substantial for the 1960 cohort (0.6469, with a standard error of 0.1417$)$. We found that for both cohorts, the changes in the results were mostly quite trivial after the residual terms were added in the model. The logarithms of baseline hazards for the model with unobserved heterogeneity and for ones without such a term are in fact essentially identical for the 1950 cohort (see Figure 5a). The new coefficients are only slightly different for the other covariates, too. This conclusion does not exactly hold true for the 1960 cohort. The relative risks for women aged 16 to 19 and for childless women were obviously somewhat enlarged. In addition, the logarithm baseline hazard for the 1960 cohort moved downward (see Figure 5b). We did not find that any coefficients reversed in the opposite direction, therefore, we could further conclude that the divorce pattern of Swedish women that we described earlier, based on the child age model, still holds true. (We also tried to add the residual terms in our Parity model; however, we failed to make the aML program converge).

(Table 2 about here)

(Figures $5 \mathrm{a} \& 5 \mathrm{~b}$ about here)

(Figures $6 \mathrm{a} \& 6 \mathrm{~b}$ about here)

In Section 3.4, we made an interaction between parity and the age of the youngest child in a model without the unobserved heterogeneity term. Now we perform the same interaction in the same model but add the unobserved heterogeneity term. We plotted Figures $6 \mathrm{a}$ and $6 \mathrm{~b}$ in order to show the results and draw a comparison with Figures $4 \mathrm{a}$ and $4 \mathrm{~b}$. We did not find any dramatic changes.

\section{Conclusion}

According to this study, the 1950 cohort and the 1960 cohort had the same pattern of divorce. The 1960 cohort had a higher baseline hazard, i.e. a higher risk level than that of the 1950 cohort. Those who married as teenagers had the lowest marriage 
cohesion in both the 1950 and the 1960 cohorts, which is consistent with other demographic studies. The age effect was stronger in the 1960 cohort. Women with a premarital birth had a higher risk of divorce than those without a premarital birth, as we expected. When the effect of age of the youngest child is controlled for, the effect of premarital births tends to be less substantial. Having children strongly stabilizes a marriage. Being pregnant with the first child or raising an infant reduced a woman's risk of marriage disintegration strongly. However, when the youngest child gets older, mothers begin to be exposed to a higher risk of divorce again. Those who only have one child five years after the first birth had a divorce risk at least as high as the corresponding relative risk of childless women.

The divorce risks of women with two or three children are very similar. Likewise, the risks for women with four and more children are proportional to the risks of two- and three-child mothers. (Women with one child above the age of two have the highest divorce risks of all mothers.) For pregnant women, the risk is low but it increases with parity. Perhaps low-parity births are more carefully planned than births at higher parities.

We did capture unobserved heterogeneity for the two cohorts. The estimated coefficients for the 1950 cohort remain almost unchanged when a heterogeneity factor was added, whereas the effect of being a teenager or childless became more evident for the 1960 cohort.

This study is based on demographic factors only, and does not address social and economic factors. Compared with previous work (Andersson, 1977), we used a different model and studied the divorce risk from the cohort perspective. The contribution of our work is that we prove the aforementioned findings by other authors once more and enlarge the existing body of knowledge on the family dynamics of Swedish women.

\section{Acknowledgements}

This study originally served as a term paper in a course on Advanced Event History Analysis taught by Jan Hoem in the winter semester of 2000/2001, in Rostock, Germany. The author would like to thank Jan Hoem for his teaching and for his many suggestions regarding this paper. The author also greatly appreciates Gunnar Andersson's suggestions on the project and Jenae Tharaldson's and Susann Bacher's editorial skills advice they applied to this paper. 


\section{Bibliography}

[1]. Andersson, G. (1997). The impact of children on divorce risks of Swedish women'. European Journal of Population, 13/2: 109-145.

[2]. Becker, G. S., Lands, E. M. and Michael, R. T. (1977). 'An economic analysis of marital instability'. The Journal of Political Economy, 85/6: 1141-1188.

[3]. Bracher, M., Santow, G., Morgan, S. P. and Trussel, J. (1993). 'Marriage dissolution in Australia: models and explanations'. Population Studies, 47: 403-425.

[4]. Erlangsen, A., Andersson, G. (2001). 'The impact of children on divorce risks of first and later marriages' MPIDR Working Paper: WP-2001-033.

[5]. Hoem, B., and Hoem, J. M. (1992). The disruption of marital and non-marital unions in contemporary Sweden', In J. Trussel, R. Haninson, and J. Tilton (eds.), Demographic Applications of Event History Analysis. Oxford: Clarendon Press, 61-93.

[6]. Hoem, J. M. (1995). 'Educational capital and divorce risk in Sweden in the 1970s and 1980s', Stockholm Research Reports in Demography No. 95.

[7]. Hong, Y. (1996). 'Patterns of divorce risk in the 1970s and 1980s for Swedish women with a gymnasium education'. Stockholm Research Reports in Demography No. 03.

[8]. Lillard, L. A. and Constantijn W. A. Panis (2000). Multiprocess Multilevel Modelling, aML release 1.0. User's Guide and Reference Manual. EconWare, Los Angeles, Caifornia. [9]. Lillard, L. A. and Waite, L. J. (1993). 'A joint model of marital childbearing and marital disruption'. Demography, 30/4: 653-681.

[10]. Lillard, L. A., Brien, M. J. and Waite, L. J. (1995). Premarital cohabitation and subsequent marital dissolution: a matter of self-selection?' Demography, 32/3: 437-457. [11]. Suchindran, C.M., Koo, H. P. and Griffith, J. D. (1985). The effects of post-marital childbearing on divorce and remarriage: an application of hazards models with timedependent covariates'. Population Studies, 39: 471-486. 
Table 1. Relative risks of divorce in first marriages

for Swedish women, $1950 \& 1960$ cohorts

(Models without unobserved heterogeneity term)

\begin{tabular}{llcl}
\hline parity model & \multicolumn{3}{c}{ child age model } \\
\hline 1950 cohort & 1960 cohort & 1950 cohort & 1960 cohort
\end{tabular}

Age at marriage

16-19

1.72

2.36

1.84

2.74

20-23

1.18

1.36

1.22

1.50

24-28

1.00

1.00

1.00

1.00

29-35

0.89

0.82

0.78

0.69

36-49

0.69

0.90

0.43

0.58

Premarital

birth

No

1.00

1.00

1.00

1.00

Yes

1.77

2.00

1.25

1.20

Parity

$\begin{array}{lll}0 & 1.82 & 2.31 \\ 1 & 1.00 & 1.00 \\ 2 & 0.64 & 0.62 \\ 3 & 0.57 & 0.48 \\ 4+ & 0.58 & 0.61\end{array}$

Age of youngest child

no child

1.67

1.51

pregnant

0.32

0.23

age 0

age 1-2

0.10

0.10

age $3-5$

0.41

0.48

age 6-8

1.00

1.00

1.24

1.16

age 9+

1.55

1.40 
Table 2. Comparisons of estimates based on the models with and without unobserved heterogeneity term

(child age model)

\begin{tabular}{|c|c|c|c|c|}
\hline & 1950 cohort & & 1960 cohort & \\
\hline & NO sigma & With sigma & No sigma & With sigma \\
\hline Intercepts & -8.4317 & -8.41676 & -7.4591 & -7.7519 \\
\hline \multicolumn{5}{|l|}{ Slopes } \\
\hline Duration below 1 year & 2.1489 & 2.1701 & 2.0063 & 2.0018 \\
\hline $1-2$ years & 0.9938 & 0.9800 & 0.7867 & 0.8023 \\
\hline $2-3$ years & 0.4108 & 0.4131 & 0.4202 & 0.4313 \\
\hline 3-4 years & 0.5149 & 0.5133 & 0.0889 & 0.1010 \\
\hline $4-7$ years & 0.0823 & 0.0802 & 0.0972 & 0.1093 \\
\hline $7-11$ years & -0.0453 & -0.0467 & -0.0755 & -0.0667 \\
\hline $11-15$ years & -0.1255 & -0.1253 & -0.0750 & -0.0690 \\
\hline \multirow[t]{2}{*}{15 years and longer } & -0.0309 & -0.0310 & -0.0483 & -0.0438 \\
\hline & \multicolumn{2}{|c|}{$\begin{array}{l}\text { (see Figure 5a for } \\
\text { logarithm of } \\
\text { baseline hazard) }\end{array}$} & \multicolumn{2}{|c|}{$\begin{array}{l}\text { (see Figure 5b } \\
\text { for logarithm of } \\
\text { baseline hazard) }\end{array}$} \\
\hline \multirow{2}{*}{\multicolumn{5}{|c|}{$\begin{array}{l}\text { Relative risk } \\
\text { Age at marriage }\end{array}$}} \\
\hline & & & & \\
\hline $16-19$ & 1.84 & 1.83 & 2.74 & 3.06 \\
\hline $20-23$ & 1.22 & 1.22 & 1.50 & 1.54 \\
\hline $24-28$ & 1.00 & 1.00 & 1.00 & 1.00 \\
\hline $29-35$ & 0.78 & 0.79 & 0.69 & 0.69 \\
\hline $36-49$ & 0.43 & 0.44 & 0.58 & 0.58 \\
\hline \multicolumn{5}{|l|}{ Premarital birth } \\
\hline Yes & 1.25 & 1.25 & 1.20 & 1.24 \\
\hline No & 1.00 & 1.00 & 1.00 & 1.00 \\
\hline \multicolumn{5}{|l|}{ Age of youngest child } \\
\hline No child & 1.67 & 1.66 & 1.51 & 1.65 \\
\hline Pregnant & 0.32 & 0.33 & 0.23 & 0.24 \\
\hline 0 & 0.10 & 0.10 & 0.10 & 0.10 \\
\hline $1-2$ & 0.41 & 0.42 & 0.48 & 0.48 \\
\hline $3-5$ & 1.00 & 1.00 & 1.00 & 1.00 \\
\hline $6-8$ & 1.24 & 1.24 & 1.16 & 1.17 \\
\hline $9+$ & 1.55 & 1.53 & 1.40 & 1.45 \\
\hline Sigma* & & 0.2740 & & 0.6469 \\
\hline
\end{tabular}

All the estimates have a $1 \%$ significant level, except for the slope for duration 2-3.

*Sigma stands for the unobserved heterogeneity term in the model. 
Figure 1. Logarithm baseline hazard, 1950 cohort

Standarized for age at marriage, parity \& age of youngest child

\section{Duration since first marriage}

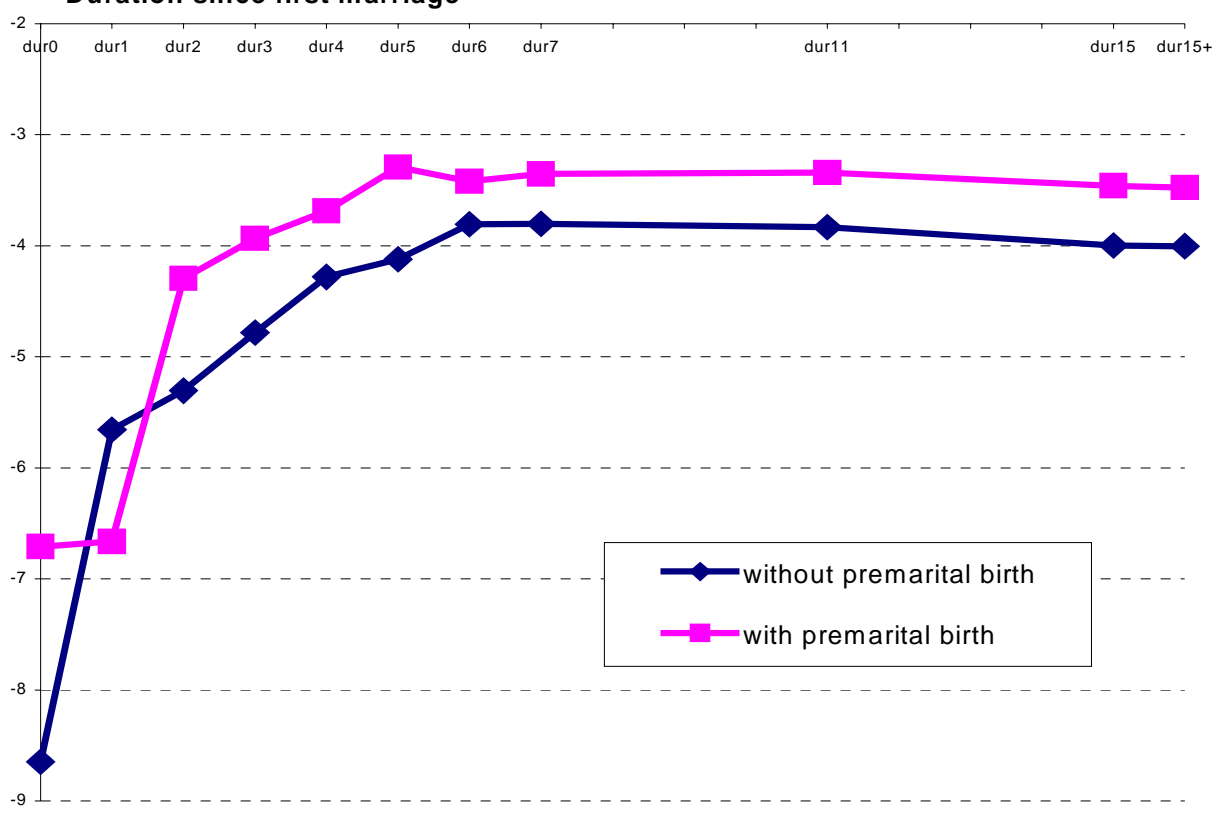

Figure 2. Logarithm of baseline hazard, 1960 cohort

Standarized for age at marriage, parity \&

Duration since first marriage age of youngest child

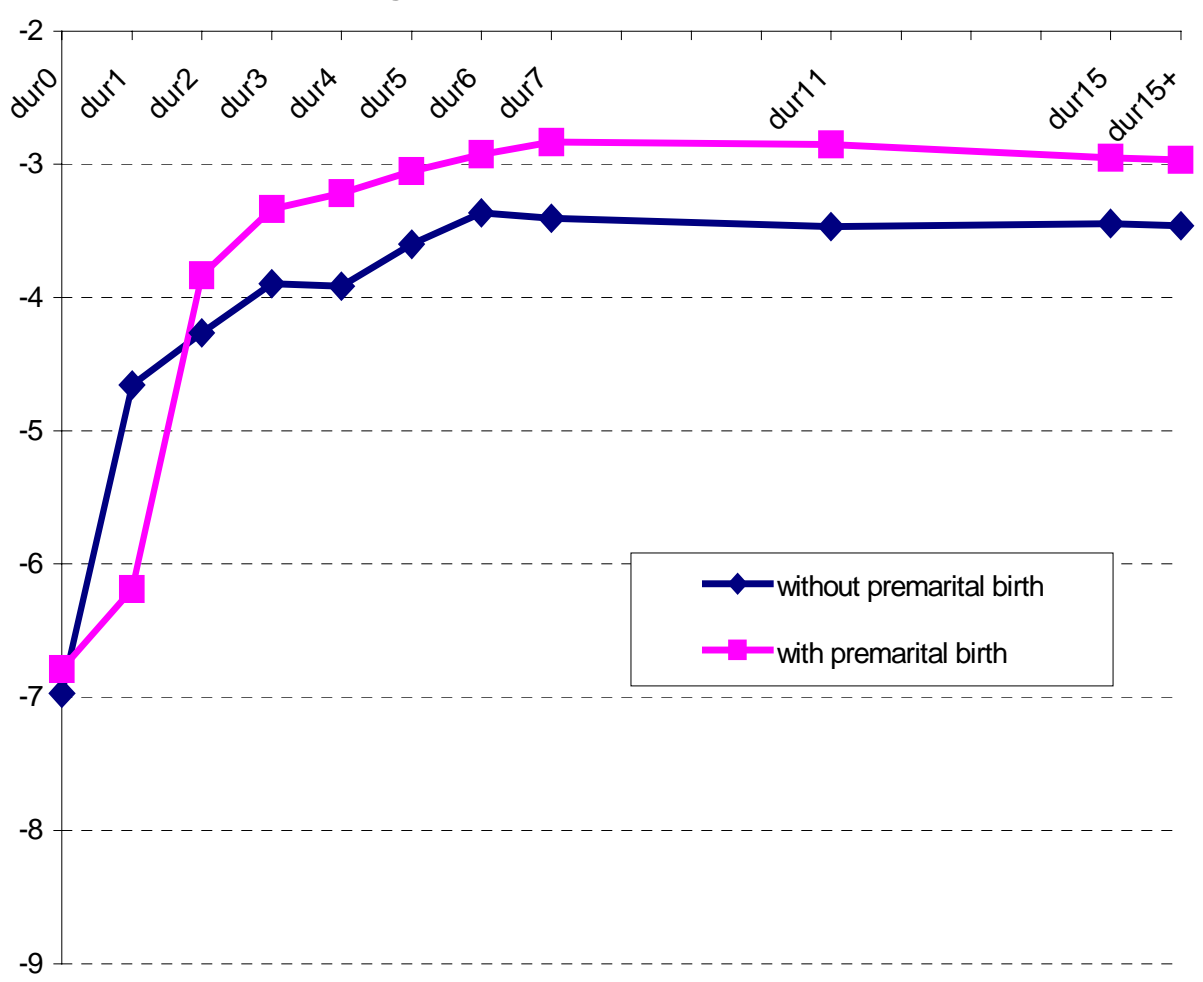


Figure 3a Logarithm of baseline hazard

Standarized for age at marriage, premarital birth \& age of youngest child (child age model)

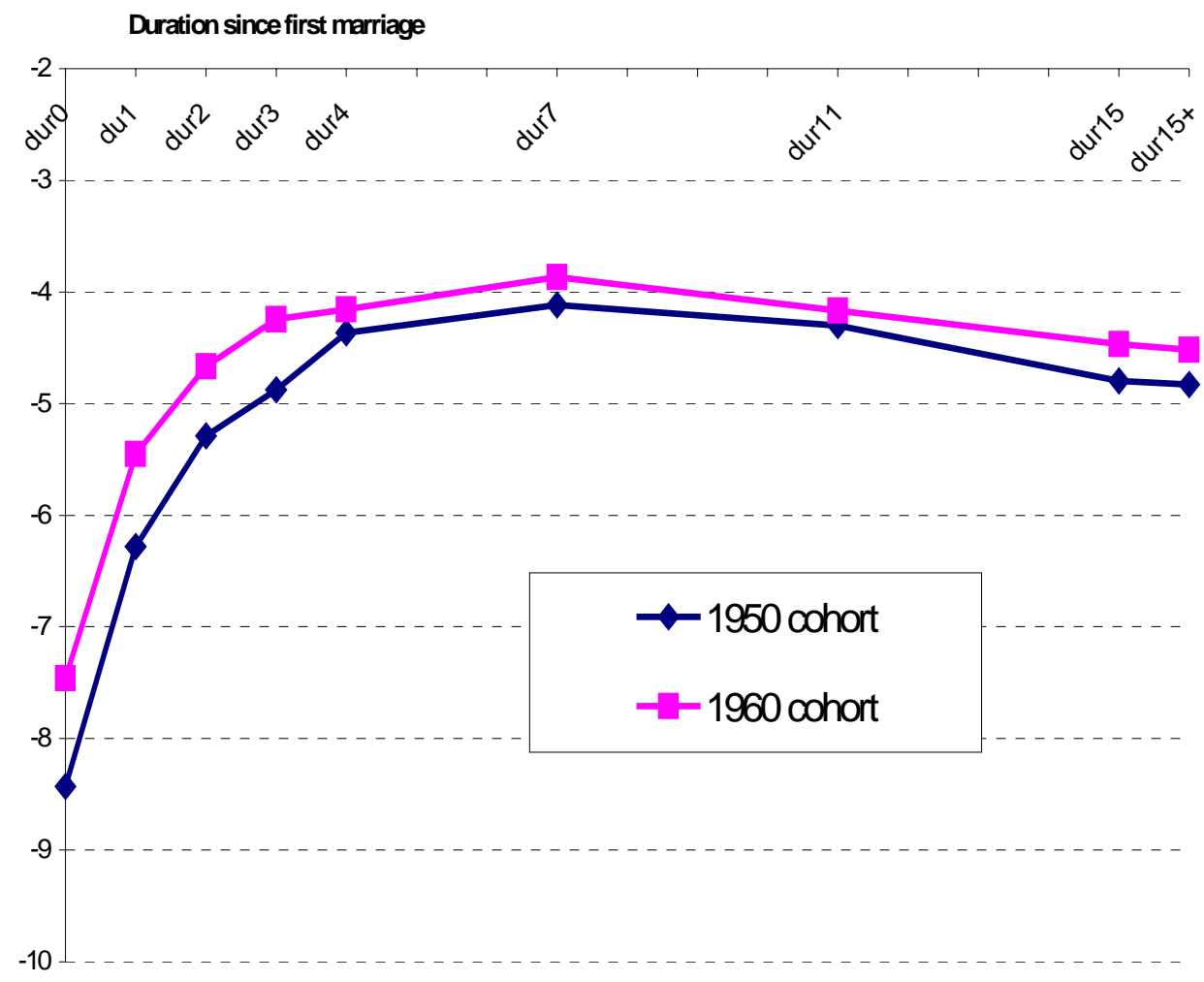

Figure 3b. Logarithm of baseline hazard

Standarized for age at marriage, premarital birth \& parity
Duration since first marriage
( parity model)

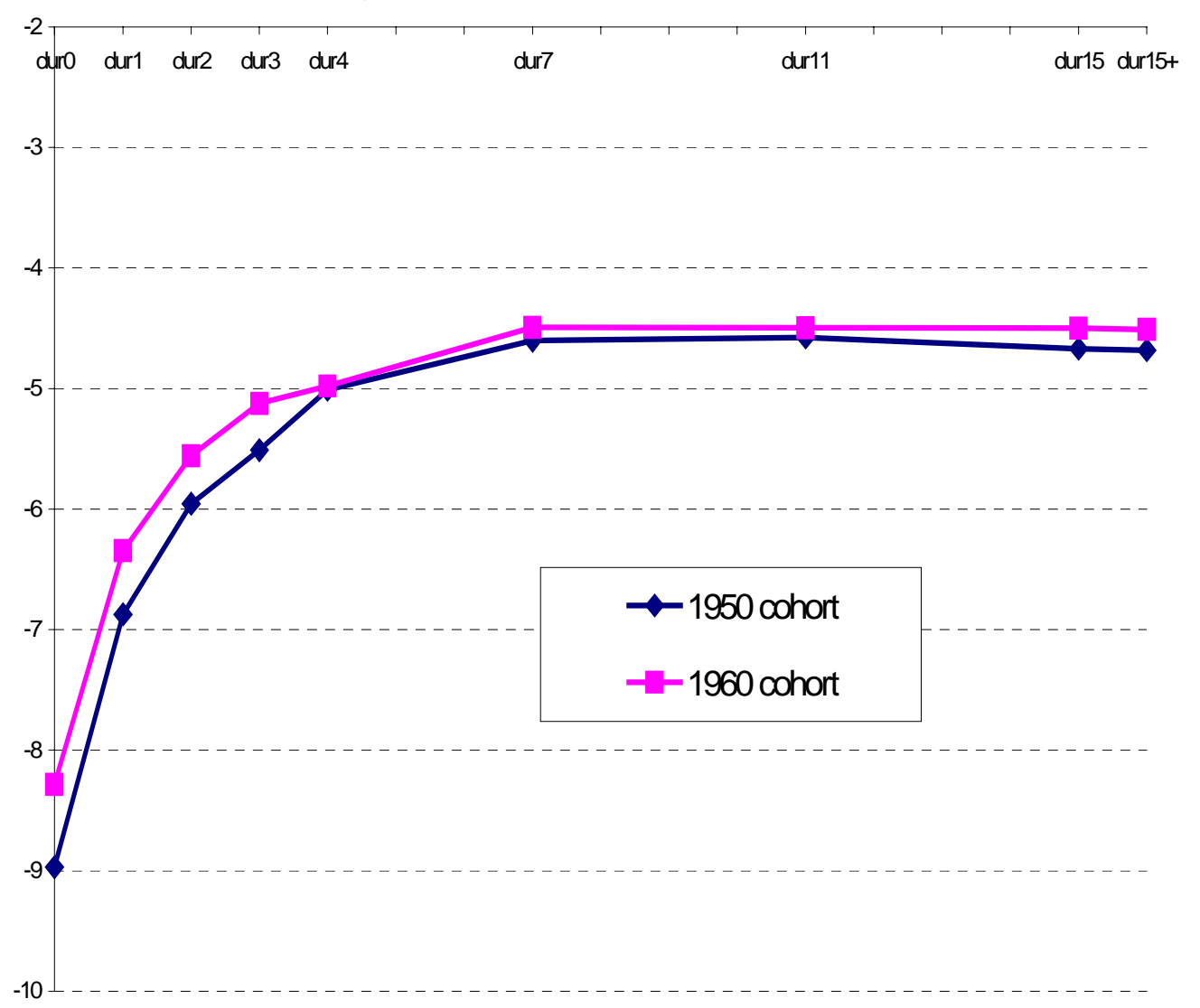


Figure 4a. Interactions between parity and age of youngest child, 1950 cohort

No unobserved heterogeneity.

Standarized for age at marriage, and premarital birth

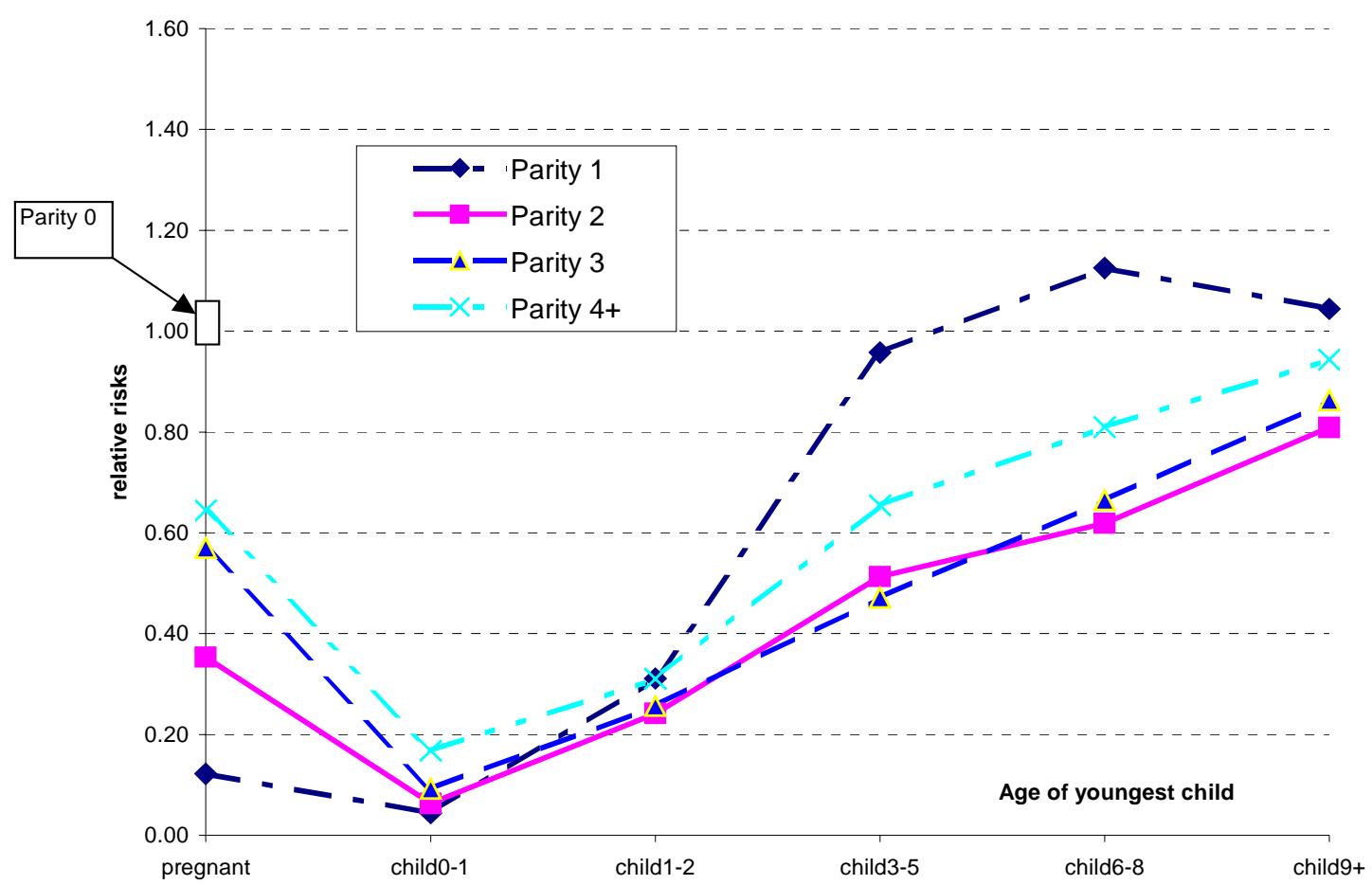

Figure 4b. Interactions between parity and age of Youngest child, 1960 cohort

No unobserved heterogeneity

Standarized for age at marriage, and premarital birth

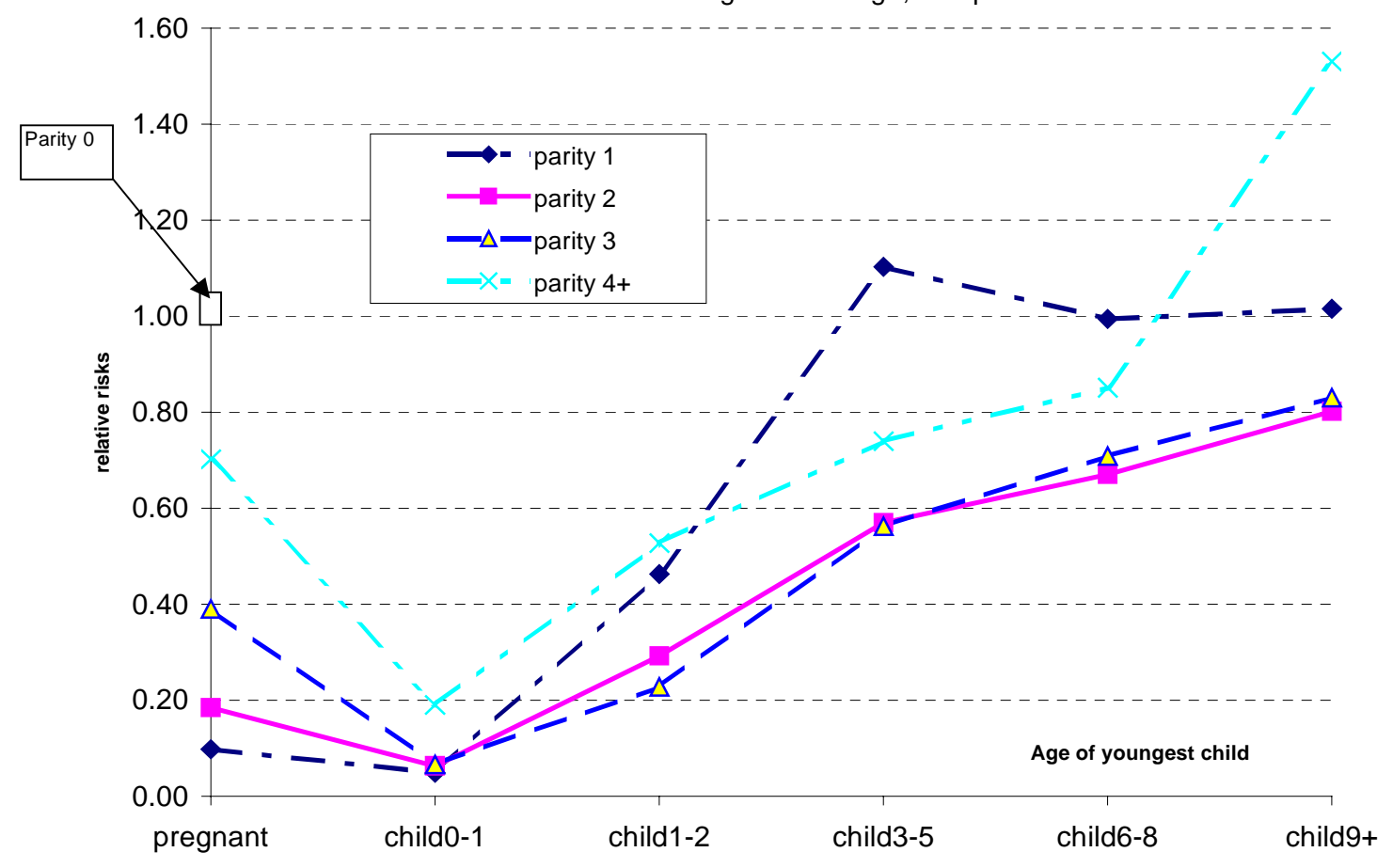


Figure 5a. Logarithm of baseline hazards,1950 cohort Standarized for age at marriage, premarital birth \& age of youngst child

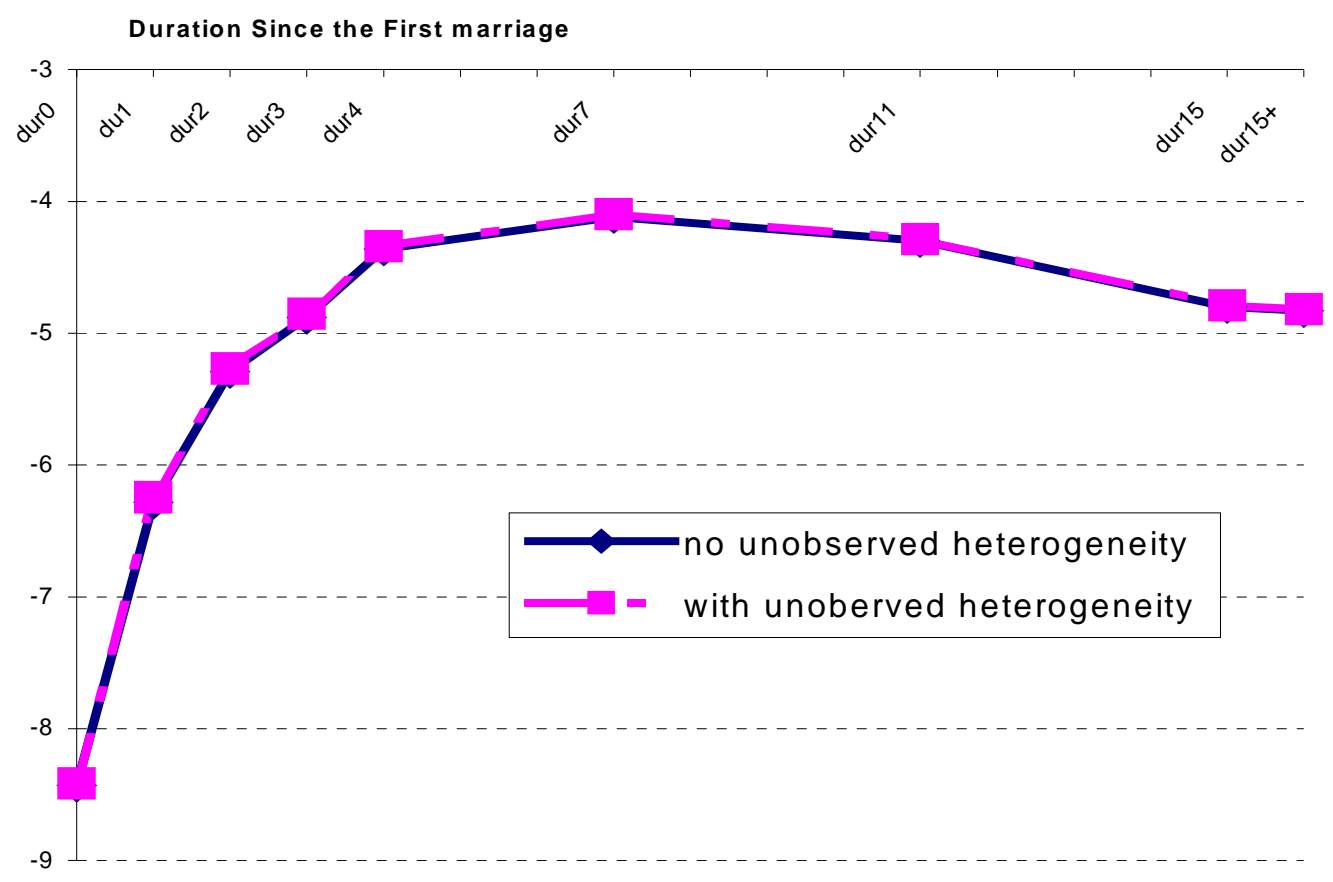

Figure 5b. Logarithm of baseline hazards, 1960 cohort Standarized for age at marriage, premarital birth \& age of youngest child

\section{Duration since first marriage}

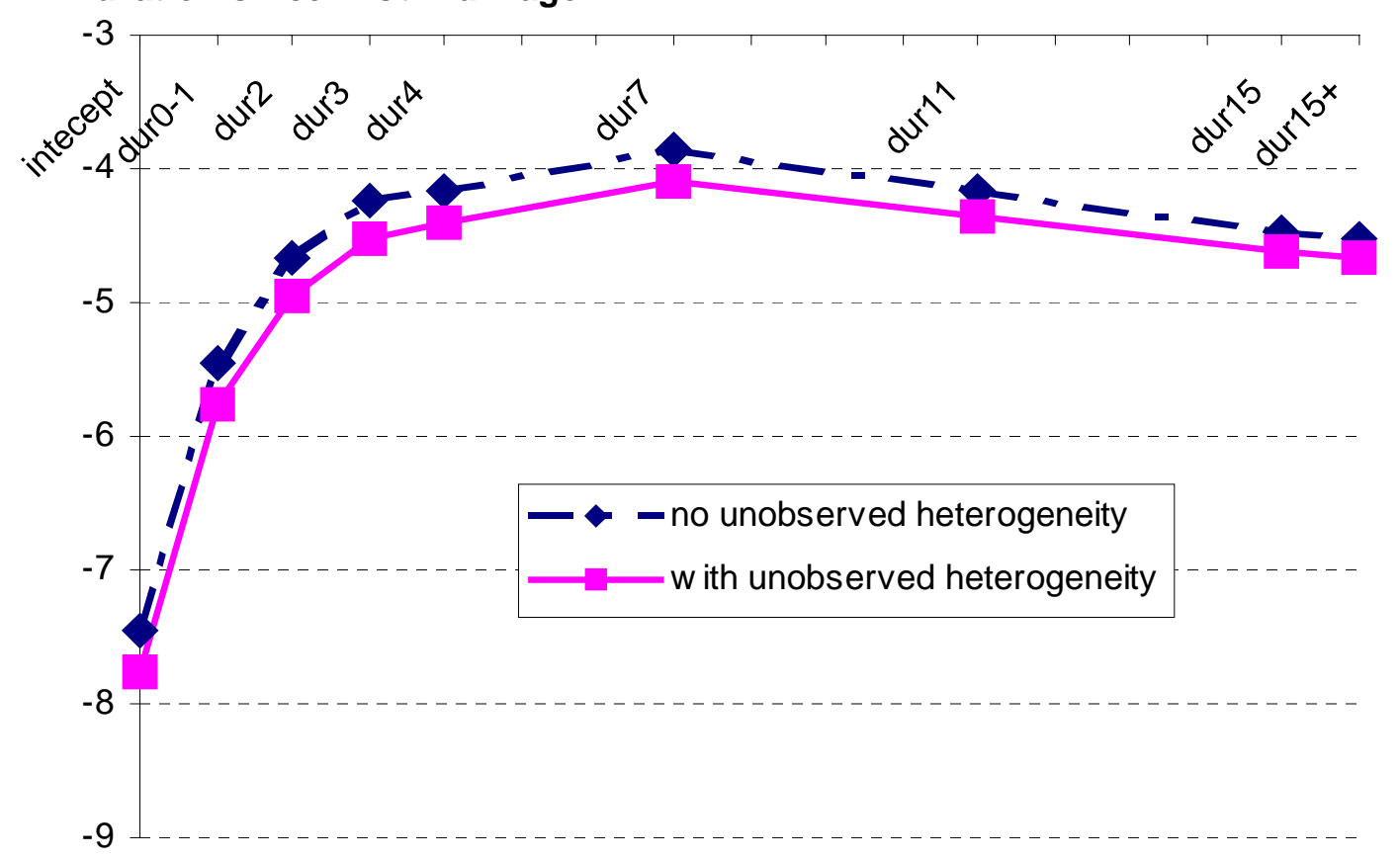


Figure 6a. Interactions between parity and age of youngest child, 1950 cohort, with unobserved heterogeneity

Standarized for age at marriage, premarital birth

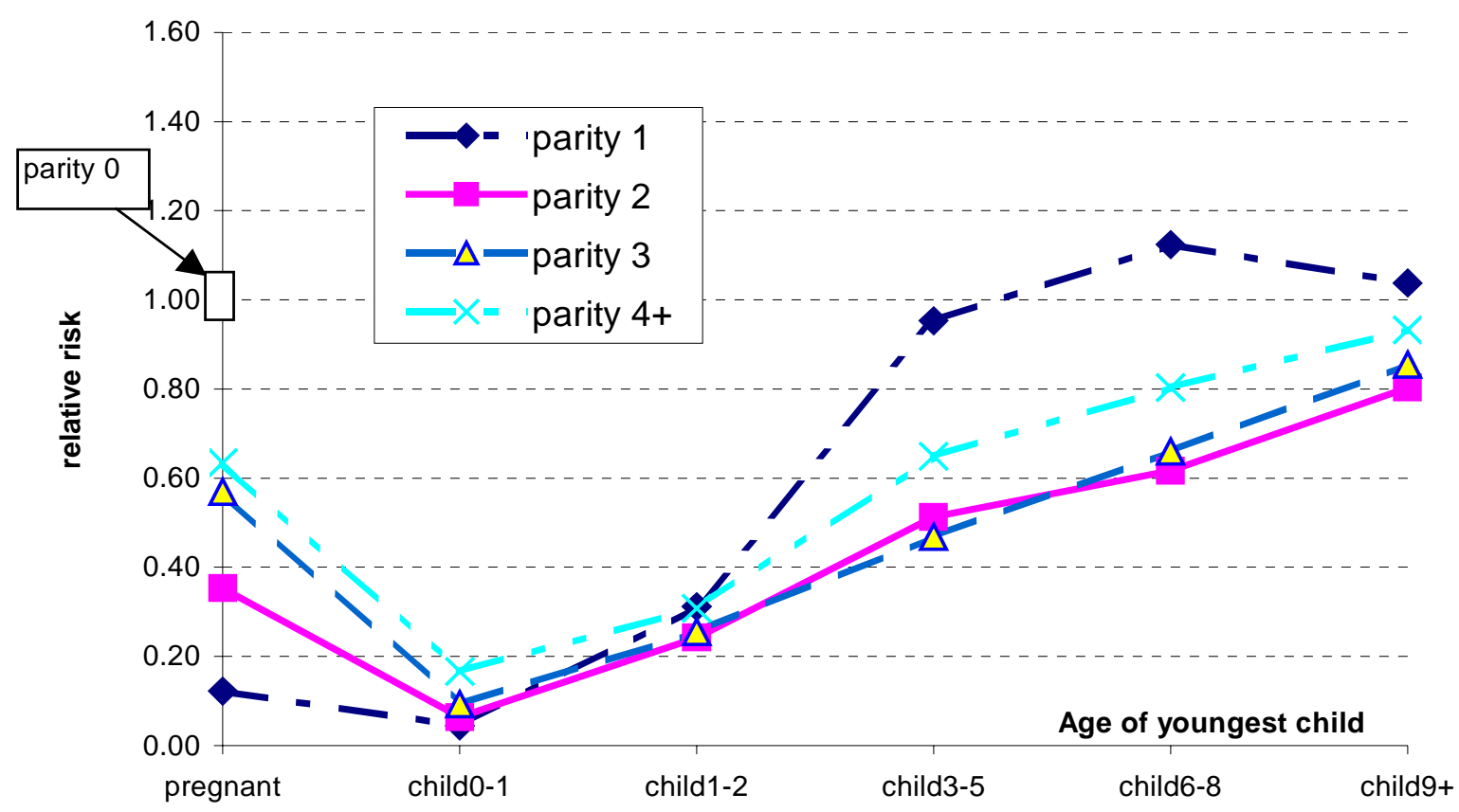

Figure $6 \mathrm{~b}$. Interactions between parity and age of youngest child, 1960 cohort, with unobserved heterogeneity

Standarized for age at marriage, prematital birth.

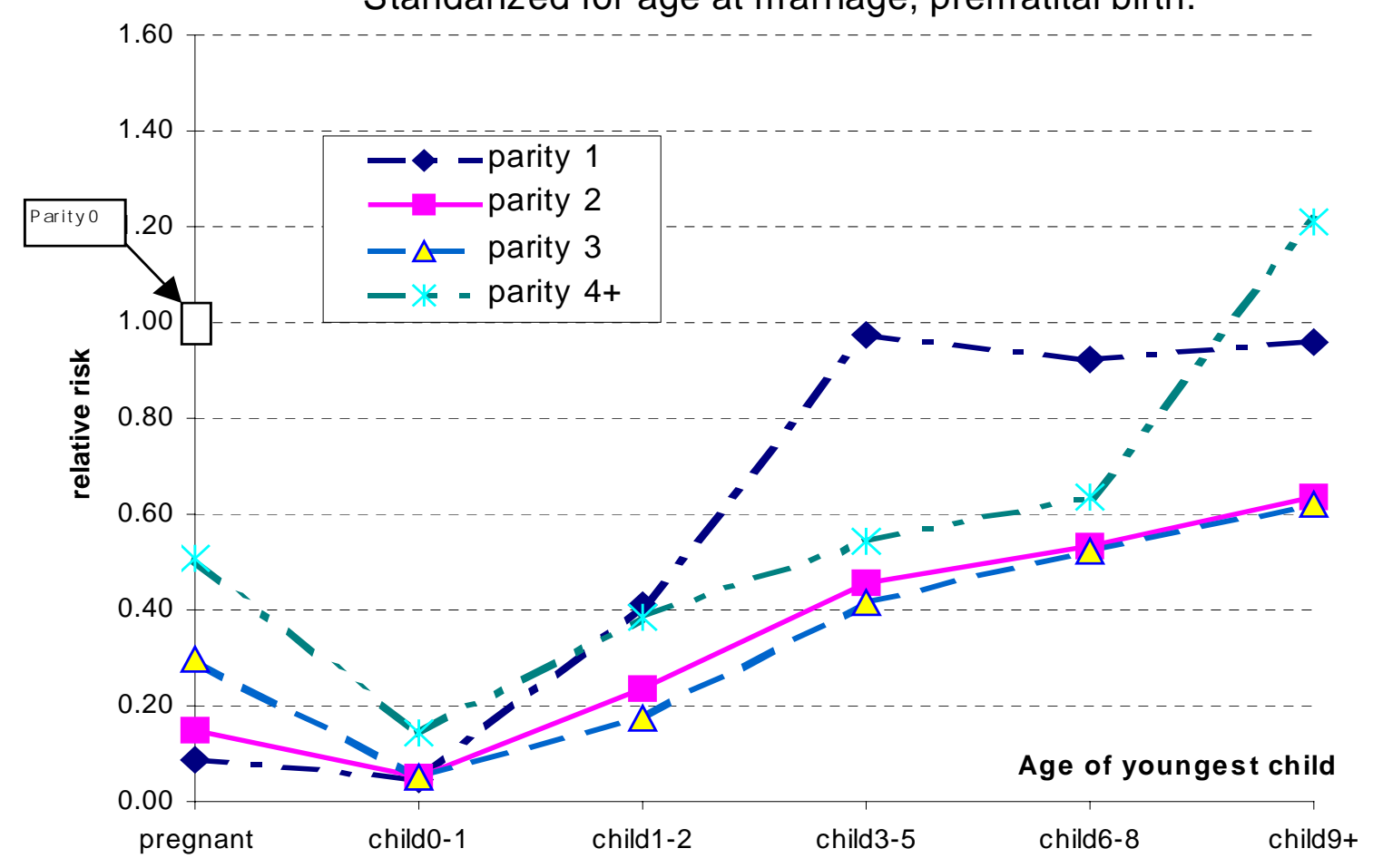

